\title{
Roberto Marx
}

\section{INTRODUCTION}

The automotive sector consists of the production of parts for and assembly of vehicles. It is the sector in which the greatest efforts have been made to modernize production and where modernization initiatives have been most tried, tested and evaluated. However, one aspect of the automotive sector which deserves much more attention is the position of small- and medium-sized enterprises (SMEs), and in particular the position of firms which belong to the automotive sector but which display certain characteristics which are very different from the larger firms which are the focus of most studies. A study of smaller firms might lead us to qualify the general conclusions of previous studies of these larger firms.

A number of medium-sized and large firms in the motor components sector have made considerable efforts to introduce Total Quality Control programmes, and the results have been good. In some cases, pressure has come from the assemblers, and in others the initiative has come from within the company. ${ }^{1}$ In the case of SMEs, the sources of stimulus and the available resources and information are very different, and as a consequence their experiences are rather different. In particular, SMEs lack the internal capacity needed to follow the path towards guaranteed quality.

This article aims to contribute to the discussion of this issue. It defines SMEs as locally-owned companies with fewer than 150 direct workers, given that the path to modernization displays markedly different characteristics when a parent company is available to provide help. ${ }^{2}$ The data is taken from studies of five small motor components companies. These supply final assemblers, other motor components firms, the replacement parts market and some customers in other sectors of industry. The main markets for these companies, however, are in the local automotive industry. Sales to other industries have never surpassed 30 per cent of total sales in the five companies studied, and only one of the companies had even a minimal export orientation. All of the five firms studied were located in Greater São Paulo, the industrial heart of Brazil, where four out of six vehicle assemblers are located. Approximately 90 percent of motor components production is located in the state of São Paulo. ${ }^{3}$

\section{PRESSURES TO MOVE TOWARDS QUALITY ASSURANCE}

The pressures on SMEs to change production methods and improve quality come from a variety of sources.

\subsection{Motor Industry Clients}

The main source of pressure to adopt new quality systems comes from client firms in the motor industry. For the last three years, large companies have sought to involve smaller suppliers in Quality Assurance systems. Small firms are pressured in a number of ways. Firstly, clients make monthly evaluations based on inspections of the products supplied by the SMEs. Secondly, SMEs are obliged to sign contracts which assure supplies of a guaranteed quality which will not be inspected by the client on arrival at the plant. Thirdly, SMEs are obliged to enter into information networks set up by the main clients to make possible rapid interchange of commercial and production data. Fourthly, the assemblers encourage SMEs to acquire CAD/CAM systems compatible with the formers' own systems. This enables electronic interchange of product and process information. Fifthly, and most importantly, periodic audits are made of suppliers by the major companies in which quality systems in use are evaluated. The model for this is based on ISO 9000, which includes a wide range of techniques which until

\footnotetext{
See, for example, the conclusions of Prado (1988) and Rocha Lima (1987).

2 See the article by Tereza Fleury in this Bulletin for evidence on this point.
}

\footnotetext{
3 Three of the five case studies were carried out for the IPEA project (Fleury and Humphrey 1992).
} 
recently were little-known in SMEs. These techniques include the following:

- Traceability. This is an information system which allows companies to locate the sources of quality problems detected at a later stage in the production process. The information available includes the date of fabrication, the lot number, the machines which worked on the lot, the persons responsible for its quality, etc.

\section{- Statistical Process Control. ${ }^{4}$}

- Failure Mode and Effect Analysis. This is an information system usually created in the course of the development of a new product. It involves identifying causes of failure for those aspects of products and their associated production processes which are critical for obtaining guaranteed quality, and then logging the remedies suggested.

- Preventive Maintenance Programmes. These specify a series of procedures (tests, checks and controls) which should be followed in order to guarantee the normal working of machinery and equipment. This should avoid or anticipate the need for corrective maintenance and thus prevent machinery being out-of-service for any length of time.

The audits which evaluate these quality procedures result in an overall score being given. Companies which receive a negative evaluation are not asked to supply new products, although they may continue to supply existing ones. Companies which are approved by this certification process are given an ongoing role in parts supply.

In spite of the pressure to improve quality systems large clients seem to provide little help to enable the small companies to meet these new demands. It is very rare for a large client to make efforts to provide guidance and help with the introduction of the new techniques that small companies are required to adopt. The study showed that SMEs receive very little support for beginning either the process of modernization in general or the introduction of specific techniques such as SPC. In the case of SPC, the large client firms do put on courses and send teaching materials to the SMEs, but they do not offer the technical assistance necessary for planning the introduction of this or other techniques.
Notwithstanding this general picture, there are signs that some assemblers are beginning to make attempts to provide more consistent support for their SME suppliers. In particular, one Japanese-owned assembler has developed a scheme in which some modernization projects in supplier firms are developed and implanted by its own engineers and technical staff. During the process (which can last from a few weeks up to two months) the assembler puts a team into the supplier company. The team diagnoses problems and directs the initial stages of implantation of the techniques and procedures judged necessary for the supplier to be able to improve its quality system. Subsequent evaluations of the supplier are based on targets established by the team, which has gained detailed knowledge of the supplier and is in a strong position to demand compliance, given that the assembler has shared know-how not previously available (for financial and technical reasons) to SMEs. Up to the present time, this type of scheme is rare, and none of the five firms in the sample were suppliers to the assembler concerned.

\subsection{Government}

The pressure to modernize coming from the government is indirect. It comes mainly from the opening up of the domestic market to imports. SMEs believe that their prices are almost always higher than those which the assemblers could obtain abroad. SMEs are aware of the risk of their output being replaced by imports as trade barriers are gradually lowered. The pressure is already evident. It was possible to observe one case where the documentation sent by an assembler to a small supplier cited the prices being paid by its parent company abroad for products identical to those produced in Brazil. The assembler was making continued purchases from the supplier conditional on its prices being lowered to the overseas price plus the remaining tariff. The owner of the small supplier believed that this was impossible to achieve.

The government also offers credit to SMEs. Schemes are available to finance purchases of equipment and training of staff. However, none of the firms in the sample revealed any interest in taking advantage of them. In one case a firm had requested support from a programme designed to train high-level personnel. The request had been approved, but three months after receiving approval the firm had not

\footnotetext{
4 See the Appendix to the Introduction to this Bulletin.
} 
been informed how or when the support would be provided.

At the time of the interviews, the SMEs looked unfavourably upon government. The mention of government as a force for modernization almost always provoked the comment that it should not interfere in matters concerning industry. Rather, it was argued that government should restrict its role to achieving macroeconomic stability, ${ }^{5}$ providing basic education and improving the county's transport and housing infrastructure.

\subsection{Employers' Associations}

In recent years, the leaders of the main association of motor components companies, Sindipeças, have declared their intention to promote discussion and diffusion of modernization in the sector. This has been done through articles in the association's magazine, conferences given by specialists, research on the diffusion of automation equipment such as CAD/ $\mathrm{CAM}$, and discussions between groups of firms on various aspects of modernization. Sindipeças has put great emphasis on the issue in recent years.

One of the ideas put forward and discussed by Sindipeças is the formation of groups of SMEs which could collectively make use of certain technologies whose cost and complexity limit their availability to small firms. An example of such a technology would be CAD/CAM. A collaborative scheme of this type would be typical of the Flexible Specialization model proposed by Piore and Sabel (1984), and analysed by, among others, Schmitz $(1989 ; 1992)$ and Ferreira et al. (1991). However, the involvement of smaller firms in the activities of Sindipeças is quite limited compared to that of larger companies, and the managers of small firms who become involved can be considered as 'being part of the minority who have already become aware of the need for modernization', according to the President of Sindipeças. The same person also argued that 'small- and medium-sized firms who have yet to be convinced of the need for change can already be considered "lost causes" - Sindipeças cannot do anything for them because there is no time left to recover the time already lost'.
If this analysis is correct, it means that an intense selection process is taking place between firms in the automotive industry. For quite a number of firms the result is already clear: they will gradually be forced out of the market because of their inability to adapt to the technical requirements of the new competitive situation in the sector. For others, everything will depend on the selection processes used by the major customers and on their own ability to cut prices and improve quality.

Clearly, the Brazilian case does not correspond to the Flexible Specialization proposed by Piore and Sabel (1984). The Flexible Specialization model is based on the Emilia-Romagna region of Northern Italy and its geographically-concentrated small firms. These firms are independent of large companies, highly competitive, use skilled labour and are interlinked through horizontal and vertical collaborative ties. The Brazilian case looks at first sight to be closer to the example of Baden-Württemberg in Germany analysed by Schmitz (1992). In this case, large firms such as Daimler-Benz, Bosch and IBM are at the centre of a regional network of small- and mediumsized component suppliers. However, in spite of the ideas put forward by Sindipeças, the SMEs in the automotive sector in Brazil have not taken concrete steps towards forming collaborative relations. Comparing the Brazilian case with Baden-Württemberg, there are a number of important differences:

- Brazilian firms are not as geographically concentrated

- local and State governments do not act as agents to promote sectorally-specific industrial policies

- there is little financial support for SMEs

- the unions play no role in the development of SME activities

- large firms do not play a positive role in developing supplier capabilities.

\subsection{Employees of the SMEs}

The role of the employees as sources of pressure for change has to be understood in the context of ownership. Most of the owners of small firms have not

\footnotetext{
5 At the time of the study, the government had induced a deep recession without managing to get inflation below 20 per cent per month.
} 
had higher education. In some cases, they are former managers of larger companies who have set up their own businesses, and in others they are people who set up their own small businesses a long time ago without any previous experience in the sector.

In many cases, owners of SMEs lack information from outside sources about quality and productivity (suffering, for example, from an almost complete ignorance of the possible applications of information technology in their businesses). As a result, they tend to be pressured from within by employees working in areas where innovation is needed, because the employees come into contact with new equipment or new organizational practices. Suggestions for change are then made to the owner, who will be aware that these changes form part of the package of innovations suggested by clients, by the government and by Sindipeças. However, the owner will have little basis on which to discuss and evaluate such suggestions for change. While employees can be sources of change in many companies, in SMEs the lack of professional background of many ownermanagers puts additional importance on the innovatory role of professionally-trained employees.

\section{THE DECISION-MAKERS IN SMALL FIRMS}

The career profile of small firms owners was referred to in the previous Section. They are either former managers of larger companies or people who have built up their own businesses from scratch. In general, businesses run by the former have a greater ability to take the modernization process forward than firms run by the latter. The first reason for this is that the former were managers in firms which probably had the organizational and technological prerequisites for the modernization processes which the SMEs now need to introduce. ${ }^{6}$ In addition, former managers continue to maintain commercial ties or friendships with managers in large companies, and this provides them with up-to-date information, a reference point with which to compare their own progress and an encouragement to change. In the absence of more developed collaborative mechanisms, this type of interchange and contact is a positive feature, albeit rather limited in relation to the problems placed by SMEs. For owners who had not had work experience in large firms, it is more difficult to take forward the modernization process. These owners lack the theoretical and practical knowledge needed to take decisions on modernization and put them into effect.

The discussion of owners and sources of information leads on to the issue of what other sources of information are available to SMEs to help them undertake the process of change. Some of these are described and evaluated below.

\subsection{Client Firms}

They have a major role in promoting modernization, but they only serve to define patterns and rules. As was noted in Section 2.1 above they provide very little guidance for SMEs on how to modernize, except in the one exceptional case already mentioned.

\subsection{Hiring of Engineers and Technical Staff}

Few SMEs hire and keep for a reasonable period of time the technical staff and engineers with the potential to coordinate the introduction of the techniques and philosophy of Guaranteed Quality. The conclusions of a study by Ferro (1984) remain valid until today. Ferro argued that in most cases one of two situations would occur:

a The owner prefers not to hire an engineer either because of the high salary that would be required compared to average salaries in the company, or because the owner would not believe that an engineer would adapt to the non-modern management structure of a small firm. These ideas about engineers are often related to concern by the owner that hiring someone with a technical education superior to his own (few women run small metalworking firms) will lead to a loss of control.

b Negative experiences of past efforts to hire engineers lead to the same conclusion.

\subsection{Consultancy}

Only one of the five firms in the sample made any use of consultancies, and its case was exceptional as will be seen below. The principle motive for this seems to be the difficulties these firms faced in specifying exactly what problems they felt could be addressed by consultants. Consultants, for their

\footnotetext{
6 These prerequisites include, for example, organization charts, standard timings for production operations, information system to
} 
part, generally end up working on the modernization programmes of medium and large firms and do not (on the whole) develop consultancy methods appropriate to the conditions prevailing in SMEs. In part, this is because the costs of such methods would be beyond the reach of such firms.

The one exception in the survey was a firm which was using staff from the University of São Paulo, who were being coordinated and monitored by the son of one of the directors, who was himself a colleague of the consultants. This company could be considered a pioneer among firms of its size in the introduction of some of the techniques demanded by the assemblers by means of processes which took account of its situation as a small firm, its management situation and its human resources profile.

Successful consultancy work in a small firm involves recognizing not only that the owner has difficulty in defining clear problems and knowing how to proceed with the process of hiring external consultants, but also that the employees of a small firm have difficulty in interacting with professional consultants, because the latter are not used to or inclined to interact with people whose procedures are not formalized, whose decisions are often intuitive and whose understanding of modern production management techniques is limited. In order to cope with this, the consultants in this case followed one basic principle: to enable the client to become capable of solving problems, by adapting the techniques used more extensively in large firms and by providing advice oriented to practical problem-solving within the firm. In most cases, the approach was to resolve problems in pilot schemes before introducing the process into the rest of the factory.

\subsection{Training and External Courses}

The firms in the sample had invested in courses external to the firms' normal activities but the results were disappointing for two reasons. Firstly, general courses (SPC, for example) are only concerned with the theory or the technical content of a particular technique. Little is said about the difficulties of implementation or how to prepare for them. The people attending such courses tend to believe, on the whole, that they will be prepared to return to their companies and implement systems such as CAD, or techniques such as SPC, Traceability or FMEA without any problem. A large part of the failures of implantation arise out of this mistaken perception.
There is a limit to what can be learnt from general courses offered to a heterogeneous audience. They cannot prepare people fully for problem-solving within their own companies.

Once again, it seems to be essential that SMEs understand what are the limits and potential of the knowledge that a course can offer. The results of the survey suggest that the use of courses as a part of ongoing activity can be recommended. They should be part of one component of the process of implanting one or more modernizing techniques within an organization. The course should mix together practical application of techniques with theory, and wherever possible they should be given by the same consultant or team which accompanies the implantation process. This facilitates understanding and the location and resolution of doubts and problems in an effective and rapid manner.

\section{THE PATHS FOLLOWED BY THE FIRMS}

In the same way that the IPEA study found no one path to modernization, the small sample of five firms does not provide an ideal or common path. It is not possible to recommend to firms where they should begin the modernization process, who to hire, how much to spend, etc. However, some conclusions can be drawn.

It is clear that a substantial shift in the profile of the SMEs which will continue to supply parts to the assemblers and first-tier component producers is taking place. The rules and procedures used by these SMEs will be defined by the certification processes used by the large firms implementing Quality Assurance schemes. While the certification is not yet being applied rigorously (in fact, price is still very often the key criterion for selecting suppliers, even when they have different quality profiles), quality assurance criteria can be considered to be a crucial determinant of confidence and they will have clear consequences in the medium and long term.

The pressures being imposed mostly by the assem-, blers have given rise to three distinct types of response on the part of the firms in the sample: a gradual withdrawal from the market, a strategy of minimal compliance and 'wait and see', and finally an awareness of the need for change and investment in modernization. Two of the firms in the sample have opted for withdrawal, seeking new customers, either in completely different sectors or among those 
assemblers and first-tier suppliers who are less demanding about quality. The second response is, in effect, also one of non-compliance with the new demands. In this case, one firm is continuing as before and not wishing to make more substantial changes. It is doing as little as necessary.

Two firms were trying to maintain their position as suppliers to the automotive sector as a whole, including the more demanding customers. These firms value their images as companies which supply the vehicle assembly industry, and this image will help them to enter new markets should they seek to diversify. In both firms, the decision-makers had previously worked in large auto firms and subsequently set up their own enterprises in the components sector.

In both these firms, priority was given to implementing the following techniques: SPC, Traceability, Improvement Groups (see the Appendix to the Introduction to this Bulletin), FMEA and basic documentation for quality procedures. Techniques related to JIT, MRP, 7 and other innovations related to the programming of production were not being considered for introduction because of the extreme fluctuations and uncertainty in the ordering of large customers.

Neither of these firms had formalized quality and productivity programmes, except for statements of intent and achievements sent periodically to large customers. In fact, even in these more qualityconscious companies, there is often a clear distinction between what the formal documents say and what really happens. This is part of the interplay between suppliers and assemblers. The latter must be aware of the gap between what is said and what is actually done, while the former is obliged to formalize decisions, and even if this is done ritualistically, it is another source of pressure for change.

Some firms are changing. The case of the firm using consultants from the University is a case in point. It is seeking original solutions through a process of trial-and-error. Initiatives of this type can only be extended to a wider range of SMEs if some institutional support is made available which can organize and lead broader programmes in this field. It seems to be clear that the costs of putting change into effect by traditional-style consultancy firms would be much

\footnotetext{
7 Materials Requirement Planning. This is a system for planning efficient production and throughput of materials on the basis of calculations of expected or actual demand.
}

more expensive than a small firm could afford. Similarly, as has been noted already, choosing consultants able and willing to develop projects in this area is very difficult. In this sense the experience of the Enterprise Initiative in the United Kingdom is interesting. It is addressed to established small firms, provides a subsidy for consultancy services and, most importantly, provides a counsellor to assess the firms needs and a contractor who matches these needs with available consultants. This scheme seems to have attracted small firm participation and left them satisfied with the results (OECD 1991: 25).

\section{CONCLUSIONS}

The introduction of quality and productivity programmes in the SMEs in the auto components sector is subject to problems not encountered in the sector's larger firms. This article has tried to show in some detail some of the problems which arise and the causes of them. Although the five firms studied are a minimal sample of SMEs in the sector, the experiences of two of them show that recently developed techniques and organizational forms which are useful in the process of quality and productivity enhancement can be introduced with some success. However, for this success to be achieved, certain conditions are required:

a techniques, and/or ways of introducing them, have to be adapted in the light of the characteristics of the Human Resources available (at all levels) in SMEs

b emphasis on the preparation and development of Human Resources by means of on-the-job training and, preferably, the use of group-working techniques

c establishing that the time taken to implement new techniques will be longer than that usually foreseen for larger firms

d provision of external guidance (from assemblers, Employers Associations, consultants or bodies linked to the government) to direct and support the process of change. ${ }^{8}$

The study has shown that a big shift is taking place in the number and characteristics of the SMEs who will remain as suppliers to the assemblers and firsttier producers in the automotive industry. For many firms in the sector today, the prospects of continuing

8 See Fleury and Humphrey (1992) for suggestions as to how this guidance might be provided. 
in it appear to be under threat, in spite of initiatives which might be taken in the short term. As has been noted above, the process of change is slow and gradual. The key aspect, once again, is not the adequacy or otherwise of techniques related to quality and productivity improvement. These can be introduced successfully. The key question is the raising of awareness of the guidance and training offered at all levels, from the owner-managers to the shop-floor workers.

Even with the gradual reduction in the number of firms supplying the big assemblers, the importance of SMEs in the sector as sources of employment, income and technological capability should not be ignored. Initiatives aimed at strengthening the position of these firms should be put into practice. Without doubt, studies of industrial districts in the Third World and the role of sectoral associations, unions, universities, research centres and government (national, regional and local) should be a priority. ${ }^{9}$ The automotive industry has often been a pioneer in industrial development, it may yet prove to be so for the upgrading of small- and mediumsized enterprises.

9 For a discussion of industrial districts, see Rasmussen Schmitz (1992).

\section{REFERENCES}

Ferreira, C., Hirata, H., Marx R. and Salerno, M., 1991, 'Alternativas Sueca, Italiana e Japonesa ao Paradigma Fordista: elementos para uma discussão sobre o caso brasileiro', Coleção Documentos, Série Política Científica e Tecnológica, No 6, São Paulo: Instituto de Estudos Avançados, University of São Paulo

Ferro, J., 1984, 'Subordinação e Dependência: Mudança Tecnológica e Mercado em Pequenas e Médias Empresas do Ramo de Autopeças', mimeo, São Paulo

Fleury, A. and Humphrey, J., 1992, 'Recursos Humanos e a Difusão e Adaptação de Novos Métodos de Qualidade no Brasil', Working Paper, Brasília: IPEA, (a revised version of this Report will appear as an IDS Research Report in 1993)

OECD, 1991, Managing Manpower for Advanced Manufacturing Technology, Paris: OECD

Piore, M. and Sabel, C., 1984, The Second Ind ustrial Divide, New York: Basic Books
Prado, A., n.d., 'A Difusão da Automação Microeletrônica na Indústria de Autopeças Brasileira e seus Impactos SócioEconômicos', mimeo, São Paulo

Rocha Lima, R., 1989, 'Difusão da Automação e de Novas Formas de Organização e Gestão da Produção no Setor Automobilístico', mimeo, São Paulo

Schmitz, H., 1989, 'Flexible Specialisation - a New Paradigm of Small-Scale Industrialization?', Discussion Paper No 261, University of Sussex, Brighton: Institute of Development Studies

- 1992, 'Industrial districts: model and reality in BadenWürttemberg, Germany', in F. Pyke and W. Sengenberger (eds), Industrial Districts And Local Economic Regeneration, Geneva: International Institute for Labour Studies

Schmitz, H., Rasmussen, J. and Van Dijk M-P (eds) 1992, 'Flexible specialisation: a new view on small industry?', IDS Bulletin, Vol 23 No 3 